\title{
MATERNIDADES À MARGEM: \\ GRAVIDEZ E NASCIMENTO NUMA INSTITUIÇÃO DE PROTEÇÃO À INFÂNCIA
}

\author{
Marginal maternity: pregnancy and childbirth \\ in an institution for the protection of infancy
}

Fernanda Bittencourt Ribeiro*

\begin{abstract}
RESUMO
Os dados etnográficos analisados neste artigo foram obtidos através de uma pesquisa realizada durante dois anos junto a um serviço de acolhimento de famílias, situado na ilha d'Yeu (França) e destinado a famílias ditas monoparentais em dificuldade. A partir de uma interrogação sobre o que a gravidez e o parto em situação de precariedade social produzem em termos de construção simbólica da maternidade, do olhar social sobre si e das relações sociais que estes momentos propiciam, a análise considera duas situações encontradas em campo: aquela das mulheres (todas já mães) que chegam grávidas nesta estrutura de acolhimento; e a das gravidezes que começam durante a residência na instituição.
\end{abstract}

Palavras-chave: gravidez; parto; marginalidade.

* Doutora em Antropologia Social, professora do Programa de Pós-Graduação em Ciências Sociais da PUCRS. 


\begin{abstract}
The ethnographic data analyzed in this article comes from a research carried out during two years at a family housing service on d'Yeu island (France) for families called "monoparental under difficulties". From the inquiry about what pregnancy and delivery under social precariousness yield in terms of symbolic building of motherhood, of the social outlook about oneself, and of the social relations that these moments propitiate. The analysis reports two situations found during the occasion: women (all mothers already) who arrived pregnant at the institution and the pregnancies started during the time of housing service.
\end{abstract}

Key words: pregnancy; delivery; marginality.

Foi realizando uma pesquisa etnográfica (2000-2002) ${ }^{1}$ junto a um serviço pertencente ao sistema francês de proteção à infância que conheci as crianças, as mulheres e os trabalhadores sociais referidos neste artigo. Por medida administrativa ou judiciária, as crianças (até treze anos) foram colocadas nessa instituição, onde residem na companhia de um dos pais. $^{2}$ Isso é possível porque uma das particularidades desse serviço - em relação aos tradicionais dispositivos de colocação de crianças existentes na França (instituição ou família de acolhimento) - é o fato de destinar-se

1 Esta pesquisa foi feita em meu doutorado em Antropologia Social, realizado na Ecole des Hautes Etudes em Sciences Sociales (EHESS), sob orientação de Françoise Zonabend. Para a realização do curso, contei com bolsa da CAPES para doutorado pleno no exterior. RIBEIRO, Fernanda Bittencourt. Une ille au milieu de la route: approche ethnographique d'un service destiné à l'accueil de familles monoparentales et à leurs enfants en danger. 2005. Tese (Doutorado em Antropologia Social) - EHESS, Paris, 2005.

2 O sistema francês de proteção à infância é dividido em proteção administrativa e proteção judiciária e compreende, além das instituições do Estado, uma extensa rede de organizações privadas. Sob responsabilidade da Ajuda Social à Infância, a missão de proteção administrativa é de natureza essencialmente preventiva e refere-se tanto a indivíduos quanto a ações voltadas para a coletividade. A proteção judiciária intervém de forma individualizada, a partir de decisão do Juiz da Infầncia, que ordena as medidas a serem adotadas. Essas medidas podem ser: observação em meio aberto, ação educativa em meio aberto e colocação provisória da criança em família de acolhimento ou instituição. Ver: MANCIAUX, Michel et al. Enfances en danger. Paris: Fleurus, 1997. p. 421. O dispositivo ao qual me refiro neste artigo é um serviço de colocação de crianças que faz parte do setor associativo e atua em parceria com o Juizado da Infância. 
ao acolhimento de famílias ditas monoparentais em dificuldade ${ }^{3}$. Assim, esse serviço é um lugar de residência provisória onde, durante um período que pode variar de alguns meses a vários anos, as famílias residentes são acompanhadas, cotidianamente, por uma equipe formada por cinco educadores, quatro assistentes maternais, uma psicóloga e estagiários que estão presentes no cotidiano dos grupos familiares. Uma outra característica não menos importante particulariza ainda mais esse serviço: trata-se do fato dele estar situado numa ilha da costa oeste da França - a ilha d'Yeu. Com 23 $\mathrm{km}^{2}$ e distante 20 quilômetros do continente, essa ilha tem 10 quilômetros de comprimento e sua largura máxima não ultrapassa quatro quilômetros. A população permanente da ilha d'Yeu é de 5.000 habitantes e $70 \%$ da economia local depende da pesca. Entre as 16 ilhas distribuídas pela fachada atlântica da França, ela é a segunda mais distante do continente.

Entre 1989 e 2002, ao menos 55 famílias (53 mães, 2 pais e 98 crianças) residiram nessa instituição por em média 15 meses. O tempo de residência, para a maioria das mulheres referidas neste artigo, ultrapassou 3 anos. ${ }^{4}$ A maioria das famílias acolhidas nesse serviço é oriunda da periferia de Paris e, portanto, a residência na instituição subentende um distanciamento em relação ao meio social de origem, o que reforça o aspecto à margem desse dispositivo, no qual o espaço geográfico da ilha sobrepõe-se ao espaço institucional. ${ }^{5}$

As mães residentes têm entre 21 e 36 anos, suas famílias são francesas de origem maghrebina, antilhesa, da ilha da Reunião, e há mais de uma geração suas trajetórias são marcadas pela relação com os serviços sociais. Na ocasião em que se mudaram para essa instituição, nenhuma delas tinha um trabalho,

3 Para fins de classificação demográfica, utilizada em estudos de população, são ditas familias monoparentais aquelas cuja residência é constituída pela mãe ou o pai e os filhos de até 25 anos. Pesquisas sociológicas demonstram que essa denominação - promovida na França nos anos 70 por sociólogas feministas que buscavam o reconhecimento da legitimidade de famílias chefiadas por mulher - foi rapidamente assimilada a representações negativas do funcionamento familiar e de seus efeitos sobre o desenvolvimento e socialização das crianças. Ver: LEFAUCHEUR, Nadine. Les familles dites monoparentales. In: SINGLY, François; COMMAILLE, Jacques (Org.). La famille: l'état des savoirs. Paris: La Découverte, 1991.

4 Em virtude da grande maioria de mulheres que viveram com seus filhos nesse serviço, refiro-me às mães para falar dos adultos residentes.

5 O Centro Autogestado de Vela e de Animação Local (CAVAL) foi fundado em 1976 a partir de um projeto de escola de vela que oferecia estágios para jovens atendidos pelo sistema de proteção à infância. Durante os anos 80, em função da resistência da população permanente da ilha em relação à presença desses jovens vindos da periferia de Paris, a associação reconverteu o projeto institucional para o acolhimento das famílias. Essa mudança de objeto de intervenção apoiou-se também em incentivos dados pelas políticas familiares aos modos de intervenção voltados à prevenção de maus-tratos na infância. 
todas dependiam da ajuda do Estado, suas condições de moradia eram precárias ou provisórias, seus companheiros estavam, freqüentemente, desempregados e são descritos como alcoólatras ou drogados, depressivos ou violentos. Foram os trabalhadores sociais com os quais estavam em contato no continente que lhes propuseram essa alternativa de residência provisória na ilha d'Yeu, a fim de evitar que as crianças fossem colocadas ou continuassem vivendo em instituição ou em família de acolhimento. Mesmo se as condições psicossociais (alcoolismo, moradia precária, desemprego) ou relacionais (conflitos no casal e com a família, suspeita de negligência ou de maus-tratos contra as crianças) dessas famílias tenham sido designadas como de risco ou perigo para as crianças, os trabalhadores sociais consideraram que a colocação das crianças em dispositivos tradicionais, que implicam na separação entre mães e crianças e, freqüentemente, também dos grupos de irmãos, não seria uma medida apropriada.

\section{Pesquisando num cotidiano à margem}

Os dados etnográficos que serão apresentados a seguir foram obtidos mediante observação participante realizada durante 2 anos na ilha d'Yeu. Ao longo desse período, a cada 2 meses residi por em média 15 dias junto às famílias na residência coletiva - Maison Familiale Cap Horn ${ }^{6}$-, que marca a primeira etapa de suas estadias na instituição. Além dessa convivência cotidiana e prolongada, a instituição autorizou-me a pesquisa nos dossiês de todas as famílias que lá residiram entre 1989 e 2002.

Nessa residência da ilha d'Yeu, nenhuma mulher é admitida por estar grávida. No entanto, uma gestante pode ser admitida enquanto acompanhante de seus filhos colocados na instituição por medida judicial ou administrativa. Acontece também que uma nova gravidez tenha início durante a estadia na instituição. Tomando como ponto de partida as gravidezes e os partos ocorridos durante o período vivido na associação,

6 Na sua aparência, essa casa não difere da maioria das casas da ilha: sua fachada é branca com as janelas azul marinho e, assim como muitas outras, tem seu nome Cap Horn escrito em ferro e colocado em diagonal entre duas das três janelas que compõem a fachada. A entrada nos espaços da casa se faz pela lateral, através de um portão de madeira. O portão de entrada - cuja abertura só não está ao alcance dos bem pequenos - dá sobre um pátio interno cercado pelas portas convergentes dos oitos quartos, da cozinha, da sala coletiva, de um escritório e da lavanderia. Sua capacidade total de alojamento é de 25 pessoas. 
focalizo neste artigo a construção simbólica da maternidade em situação de precariedade social, bem como o papel exercido por profissionais. Cabe lembrar que esses trabalhadores sociais franceses, são, ao mesmo tempo, herdeiros de uma posição associada ao controle e à vigilância dos grupos populares e imbuídos dos ideais contemporâneos de proteção à infância e de valorização da família.

Do ponto de vista institucional, o deslocamento espacial proposto às mulheres é descrito como uma ruptura, uma ocasião de virar a página. Para tanto, as características topográficas do lugar de acolhimento servem para reforçar os objetivos do projeto. Quando a possibilidade de que a família seja acolhida nessa estrutura é evocada pelos trabalhadores sociais, é preciso que a mãe manifeste seu acordo e aceite o deslocamento do grupo familiar para a ilha d'Yeu. A partir de então, o contato é estabelecido com o diretor do serviço, que avaliará a possibilidade de admissão.

Quando solicitadas a falar dessa decisão de residir na ilha, a primeira razão apontada diz respeito à possibilidade de voltar a viver ou de continuar vivendo com as crianças: "Eu escolhi vir, mas na verdade não tinha escolha." Portanto, o que no projeto institucional é definido como ruptura, no discurso das mulheres aparece como uma continuidade, e a aceitação dessa mudança para a ilha é referida como uma prova do que são capazes de fazer pelos seus filhos.

Nesse espaço geográfico dito marginal e historicamente significado como lugar de exílio, punição ou redenção - num uso da insularidade que atingiu principalmente desviantes, perigosos, contagiosos -, a condição de vida das famílias acolhidas também é dita marginal, talvez perigosa para as crianças. Incorporando a perspectiva da história social das políticas dirigidas aos grupos populares, e em especial àquelas que objetivam a proteção das crianças, cabe observar que a localização insular de CAVAL, aliada ao acolhimento de famílias, situam esta instituição ao mesmo tempo no pólo mais arcaico e mais atual das políticas de intervenção na família adotadas na França: o afastamento, a separação e a manutenção dos laços originais, o apoio à família. A coexistência de duas medidas aparentemente contraditórias reforça a hipótese que outros estudos já levantaram acerca da permanência, talvez inconsciente, de antigos operadores ainda ativos nas lógicas de ajuda e de proteção social. ${ }^{7}$

7 LE GRAND-SEBILLE, Catherine. Se laisser affecter par l'autre: approche anthropologique de l'accompagnement. In: DUMONT, Brigitte et al. Accompagner. Paris: Érès, 2000. 
Essas particularidades que podemos identificar nesse dispositivo contemporâneo de normalização da família, que se revelam significativas quando colocadas em perspectiva com a história social das relações entre as instituições de controle social e os grupos populares, permitem que eu me refira às gravidezes e aos partos ocorridos nesse contexto como situações de maternidade à margem. Zonabend ${ }^{8}$ utiliza essa categoria para designar nascimentos que ocorrem fora das normas sociais tradicionalmente admitidas, em circunstâncias hostis, precárias ou particulares do ponto de vista social, psicológico e/ou espacial. Esses nascimentos são particulares na medida em que, por alguma razão de ordem psicossocial (grande pobreza, ausência do pai, abandono da mãe) ou biológica (inseminação artificial, bebê de proveta), o conjunto de condutas, práticas e rituais que visam acolher a criança e através das quais se instaura a negociação social que envolve os pais e a comunidade local em torno de cada nascimento não se realizam plenamente ou precisam ser reinventados. A fim de situar a experiência de maternidade de minhas interlocutoras, retomarei brevemente, e de forma não exaustiva, significados da gravidez, da maternidade e da paternidade descritos por antropólogos que realizaram suas pesquisas junto a grupos populares.

\section{Entre prova, prestígio e laço social}

Analisando, a partir de contextos específicos, a dimensão simbólica associada à gravidez por mulheres e homens vivendo em condições de precariedade material, estigmatizados por suas trajetórias e condições de vida, etnólogos identificaram aspectos relacionados às noções de prova e de prestígio social. Retomemos alguns exemplos.

Petonnet, a propósito de casais da periferia de Paris, afirma que as "mulheres têm somente suas gravidezes a dar a homens que não têm outros meios de provar a virilidade" ". Na mesma ordem de idéias, Tillard vê na gravidez a prova da capacidade de engendrar ou a verificação da

8 ZONABEND, Françoise. Naître en marge. Gradhiva, Paris, n. 19, p. 49-51, 1996.

9 PETONNET, Colette. On est tous dans le brouillard. Paris: Galilée, 1985. p. 117. Todas as traduções de textos franceses foram feitas pela autora. 
competência reprodutiva do homem e da mulher. ${ }^{10}$ Essa antropóloga, que pesquisou junto a famílias de um bairro popular de Lille, no norte da França, constata algo que também ouvi das mulheres residentes em CAVAL: a afirmação de que seus filhos não foram desejados, que eles são acidentes. A partir desses dados recorrentes, podemos propor que a origem acidental permite tornar socialmente aceitáveis essas gravidezes difíceis de explicar quando a contracepção é acessível e as condições de vida são marcadas pela precariedade.

Schwartz, interpretando o número de filhos de casais em dificuldade social, afirma:

As famílias atingidas pelo desemprego, mesmo de longa duração, não renunciam à fecundidade. Não somente para as mulheres, mas também para os homens, privados da legitimação pelo trabalho, a fecundidade constitui uma valorização narcísea eletiva, assim como um modo de defesa contra a falta, a abundância dos corpos substituindo a abundância dos bens. ${ }^{11}$

Longe da França, Fonseca, tratando da maternidade e da paternidade num contexto de extrema pobreza no Brasil, indica o papel valorizante cumprido pelas crianças para homens que não conseguem assegurar a tarefa de provedores no espaço doméstico:

Para os homens também, ser pai é uma fonte de prestígio. Uma mulher de 46 anos que recém tinha tido um filho insistia muito sobre a participação do marido: "Meu velho está aposentado por causa de um problema de saúde, mas não tem outro problema!" Da mesma forma, não se espera muito para levantar dúvidas sobre a virilidade de um recém-casado se sua mulher não engravidar logo em seguida ao casamento. ${ }^{12}$

10 TILLARD, Bernadette. Dire la grossesse. In: KNIBIEHLER, Yvonne (Org.). Repenser la maternité. Condé-sur-Noireau: Corlet, 1999. p. 33-38.

11 SCHWARTZ, Olivier. Le monde privé des ouvriers. Paris: Presses Universitaires de France, 1990. p. 138.

12 FONSECA, Claudia. Crime, corps, drame et humour: famille et quotidien dans les couches populaires brésiliennes. 1993. Tese (Doutorado de Estado em Antropologia) - Université de Paris X, Nanterre, 1993. p. 430. 
Em relação às mulheres que conheci na ilha d'Yeu, é preciso levar em conta o peso da dúvida - implícita na medida de colocação das crianças na instituição - a respeito de suas capacidades maternas. Acompanhando-lhes num cotidiano em que a prática da maternidade está sob observação, levantei a hipótese segundo a qual a gravidez representa uma ocasião privilegiada para a afirmação desse estatuto de mãe que lhes confere um lugar respeitável na sociedade, assim como para o estabelecimento de laços sociais. Não esqueçamos que foi por causa de seus filhos que foram admitidas nesse serviço e que uma equipe de profissionais lhes acompanha diariamente, avaliando e vigiando suas maneiras de agir, mas também lhes ajudando, apoiando no cuidado das crianças, no acompanhamento da escolaridade, das condições de saúde etc. Como veremos a seguir, ao longo da gravidez, a ajuda virá da equipe educativa, mas também de outras residentes e dos serviços de solidariedade existentes na ilha.

\section{Chegando grávidas}

"Ela não hesita a se refugiar atrás de sua condição de mulher grávida ou de mãe inexperiente quando isto lhe convém."

(Dossiê institucional)

Emilie e Estela estavam grávidas quando foram admitidas em CAVAL. A primeira já era mãe de dois meninos (4 e 2 anos) e a segunda de quatro crianças - dois meninos e duas meninas com idades entre 3 e 8 anos. Antes de virem para a ilha, os dois meninos de Emilie estavam vivendo em instituição, uma ação de despejo tinha sido movida contra ela e seu companheiro (pai de seu terceiro filho) era acusado de maus-tratos contra o menino de dois anos.

Estela, antes de ser admitida na associação CAVAL, morava com um companheiro e três de seus quatro filhos. Um dos meninos já estava vivendo em familia de acolhimento em função de acusações de maus-tratos que pesavam contra a mãe. A alternativa da mudança para a ilha foi decorrência do fato de Estela ter abandonado sua residência, no dia em que teria presenciado seu companheiro abusar sexualmente de sua filha mais velha: 
Daí eu arrumei minhas coisas, peguei as crianças e fui falar com a assistente social. Eu disse pra ela: Estou na rua com meus três filhos e grávida... Ela me colocou num abrigo por uma semana e um dia chegou dizendo: ou você vai morar na ilha d'Yeu, ou nós teremos que colocar as crianças em instituição. (DIÁRIO DE CAMPO)

Quando conheci Estela, sua filha, nascida durante a estadia da família na ilha d'Yeu, já tinha um ano. Chegando grávidas em CAVAL, essas mulheres, desacreditadas ${ }^{13}$ enquanto "boas mães", expressam o sentimento de estar agindo pelo bem da criança que vai nascer. Emilie, por exemplo, considera que Théo, o bebê que ela esperava quando foi admitida nesse serviço, foi o único de seus filhos a nascer em boas condições. Quando comecei a pesquisa, Emilie estava no sexto mês de gravidez e preparava a chegada de Théo. O essencial do enxoval e dos diversos utensílios necessários para o bebê foi doado pelo Seguro Católico da ilha. Uma ex-residente lhe enviava pelo correio roupas que não serviam mais a seus filhos, Emilie comprou algumas coisas e a estrutura de acolhimento lhe deu outras. No final da gravidez, me convidando a ver o enxoval do bebê, ela anunciava: "Tu vais ver quanta coisa eu tenho! A quantidade de lençóis... Tem até demais!"

Tanto na situação de Emilie quanto na de Estela, a gravidez em curso era um dos aspectos que compunha a problemática familiar no momento da admissão no serviço. Associada ao perigo atribuído ao comportamento de seus companheiros, podemos pensar que a gravidez tenha contribuído para a admissão das duas nesse lugar raro onde se conjuga colocação de crianças e presença de um dos pais. Para essas duas mulheres, a gravidez parece ter sido uma fonte de novas relações e motivo de mobilização social em nome do estabelecimento do laço mãe-criança. Ou, em nome da maternidade, essa condição que afirmam ser o que têm de mais importante na vida.

A partir da admissão, a equipe que lhes acompanha atua com a intenção de proteger a criança a nascer do risco potencial que as condições de vida ou as características da mãe e do pai representam. Assim, no dia-adia, os profissionais estão atentos ao que interpretam como expressões do vínculo mãe-bebê e, como veremos mais adiante, no momento do nascimento, ocuparão o lugar dos familiares e/ou próximos.

13 Goffman utiliza a categoria desacreditado para caracterizar a condição na qual o estigmatizado assume que sua característica distintiva já é conhecida ou imediatamente evidente. Ver: GOFFMAN, Erving. Estigma: notas sobre a manipulação da identidade deteriorada. Rio de Janeiro: Guanabara Koogan, 1988. p. 14. 


\section{Concepções embaraçantes}

"Valérie vai dar à luz outra criança no mês de janeiro
de 1994, ela desejou esta criança e ninguém conseguiu convencê-
la de interromper a gravidez."

(Dossiê institucional)

Essa nota diz respeito a uma jovem de 21 anos que chegou à instituição com duas crianças. $\mathrm{O}$ anúncio de uma gravidez durante a estadia na instituição é fonte de tensões com a estrutura de acolhimento. A concepção de uma criança quando a mulher é desacreditada em suas funções maternas e suas condições de vida não lhe permitem criar sozinha os filhos que ela já tem é particularmente "embaraçante". Do ponto de vista institucional, a gravidez iniciada durante a residência no serviço confirma a falta de discernimento da mãe ou sua incapacidade de agir de forma coerente com a realidade. Como afirma Y. Knibiehler em relação à maternidade em nossos dias:

O domínio da contracepção dotou as mulheres de uma responsabilidade assustadora. Só devem nascer as crianças "desejadas". Aquela que ousa lhes impor a vida deve poder assegurar-lhes as melhores condições de existência. ${ }^{14}$

Quando não é caso, paradoxalmente, "ser uma boa mãe" parece implicar na decisão de renunciar a ter mais um filho. Claudete e Simone, residentes na instituição há dois meses, engravidaram um mês depois da admissão, por ocasião de uma viagem ao continente para as festas de fim de ano. ${ }^{15}$ As duas, nas conversas cotidianas com as outras residentes e os membros da equipe, colocavam-se a mesma questão: ter ou não ter a criança. ${ }^{16}$ Simone dizia querer interromper a gravidez, mas sua tomada de decisão era cheia de hesitação, de dúvidas, de interlocução com a equipe educativa e com seu ex-companheiro, que continuava morando na periferia de Paris.

14 KNIBIEHLER, Yvonne (Org.). Repenser la maternité. Condé-sur-Noireau: Corlet, 1999.

p. 42 .

15 Corroborando as críticas à utilização da designação monoparental na França, nesse contexto, ela também tende a obscurecer a existência de um homem na vida das mulheres recebidas nesse lugar "enquanto mães".

16 Cabe lembrar que na França a possibilidade de interrupção voluntária da gravidez (IVG) é assegurada pelo serviço público de saúde. 


\begin{abstract}
“A recém falei com ele pelo telefone e lhe disse que não vou ter este filho. Eles [a equipe educativa] disseram que sou eu quem decide. Eu disse pra eles que não vou ter... O problema é que sou muito crente e tenho a impressão de cometer um assassinato. Tenho a impressão de matar um ser humano." (DIÁRIO DE CAMPO)
\end{abstract}

Para as mulheres que investem na carreira profissional, o discurso da falta de "desejo de criança" permite recusar a gravidez; essas mulheres designadas como vivendo em situação de risco para as crianças dizem não ter planejado seus filhos. No entanto, isso nem sempre é suficiente para que se digam capazes de lhes recusar. No contexto em que vivem, a afirmação discursiva do "desejo de criança" não faz delas "boas mães". Mas, quando o acidente acontece, qualquer que seja a decisão sobre a continuidade ou interrupção da gravidez, ele significa uma possibilidade para que se afirmem como "boas mães": podem agir de maneira "responsável" e interromper a gravidez, decidir colocar o filho em adoção no momento do nascimento e dizer "ele terá uma vida melhor com outra pessoa" 17 ou, ainda, ter a criança e buscar ser admirada pela coragem da decisão. Levada a termo ou não, a gravidez permite-lhes colocar o estatuto de mãe em coerência com a concepção ocidental na qual "os momentos essencialmente maternais são a gravidez e o nascimento" 18 .

Uma mulher como Simone, que parece decidida a interromper a gravidez, pode fazê-lo e ao mesmo tempo apresentar-se como uma boa mãe, pois, segundo ela, a posição adotada vai poupar seu filho de um futuro infeliz. No entanto, a possibilidade de afirmar-se pela maternidade coloca-se também quando a decisão vai ao sentido oposto. Nesse caso, quando falam da recusa do aborto, é com orgulho que o fazem. Vejamos o exemplo de Mariline, que engravidou de seu nono filho durante o período de residência no serviço.

17 Na França: "Toda mulher grávida pode parir em segredo em qualquer hospital ou maternidade pública onde, obrigatoriamente, será atendida. Ela pode solicitar o segredo de sua admissão, nenhum documento lhe será exigido e nem passará por nenhum controle. Os custos de hospitalização são assumidos pela Ajuda Social à Infância. Este parto, em razão de seu anonimato, é chamado 'parto sob X'." (THÉVENET, Amédée. L'aide sociale en France. Paris: PUF, 1998). Essa alternativa não era cogitada pelas mulheres que conheci.

18 DELAISI DE PARSEVAL, Geneviève. La part du père. Paris: Seuil, 1981. p. 42. 
"Quando engravidei, contei para algumas residentes, mas não à CAVAL. Eles me chamaram para uma reunião e me perguntaram: Então a senhora está grávida? Sim, estou grávida. Perguntaram se eu queria abortar, eu disse que estava fora de questão!” (DIÁRIO DE CAMPO)

Tereza conta que seu pai teria lhe oferecido dinheiro para que abortasse quando engravidou de seu segundo filho: "Neste momento houve um corte... Hoje quando olho pra ele... [o menino de dois está sentado em sua frente] Mesmo se ele me faz pagar todos os meus pecados..." (DIÁRIO DE CAMPO)

\title{
Nascimentos à margem
}

\author{
"Mamãe, tu quis ter três filhos?" - pergunta Christian à Emilie durante \\ o jantar. \\ "Francamente não. Mamãe era muito jovem e queria se divertir... Mas \\ primeiro veio tu, depois o Daniel e depois o Théo." \\ "Mas tu quis?" \\ "Se eu não quisesse vocês não teriam nascido e agora que vocês estão aqui \\ eu estou feliz." (DIÁRIO DE CAMPO)
}

Como observei anteriormente, quando as conheci, o bebê de Estela já tinha nascido e Emilie estava ocupada em levar a termo sua gravidez e a preparar a chegada do bebê. Chloé e Théo nasceram na mesma maternidade, situada no continente. Para as mulheres residentes em CAVAL, quando o bebê nasce antes da data prevista, a partida para a maternidade é feita de urgência: "A gente vai de helicóptero e nem paga" - observa Emilie. Nesse caso, os bombeiros da ilha são encarregados de acompanhar a parturiente. Foi o que aconteceu com Emilie e Estela. A filha de Estela nasceu prematura no oitavo mês de gravidez e o menino de Emilie, duas semanas antes da data prevista.

Um dia ela voltou apreensiva de uma consulta médica no continente porque a cesariana tinha sido marcada: 


\begin{abstract}
"O bebê é chato, está sentado, não quer mudar de posição e meu colo está aberto. Ele não pára de se mexer, mas não muda de posição. Eu tenho medo de sofrer, mas vamos ver, é pro dia 7 de junho [estamos na metade de maio], o médico disse que não devo fazer esforço, mas o bebê está pronto pra nascer." (DIÁRIO DE CAMPO)
\end{abstract}

De forma deliberada ou não, o fato é que Emilie não seguiu as recomendações médicas de repouso e intensificou suas atividades. No dia seguinte a essa consulta, na qual a abertura do colo do útero foi diagnosticada, ela foi de bicicleta ao Seguro Católico buscar o que faltava para o bebê. Nesse mesmo dia, fizemos um passeio, acompanhadas de uma educadora e das crianças, a uma praia da ilha, e Emilie subiu no alto das pedras para tirar uma foto... Apesar de todos os conselhos (o meu inclusive) de repouso, ela fazia planos de voltar para casa, fazer uma faxina e passar roupa. Na contracorrente da atual tendência de programação do nascimento, Emilie, apesar de seu medo de sofrer, parece preferir a fisiologia natural do parto. A data marcada da cesariana a incomoda também, pois, durante a gravidez, sempre passou mal no barco e gostaria de evitar esse mal-estar no momento de ir para a maternidade. Passado o dia 7 de junho (data da cesariana), quando telefonei para ter notícias suas, Emilie me contou que o bebê tinha nascido de maneira natural, cinco dias depois que fui embora.

\footnotetext{
"Fui de urgência para a maternidade à uma hora da madrugada!"

"Então foste de helicóptero..."

"Sim, como previsto! Ele não mudou de posição, mas tudo se passou bem. Não tive peridural nem nada, senão nós dois correríamos risco de vida! Foi à la selvagem, mas eu consegui." (DIÁRIO DE CAMPO)
}

Visto que Chloé nascera prematura de oito meses, Estela também partiu da ilha de urgência. As falas das duas mulheres a respeito da partida para a maternidade nos colocam diante de uma situação única na relação das residentes com a equipe educativa e em particular com o diretor da instituição. O parto lhes fornece uma ocasião de se apresentar como mestres de uma situação; os papéis se invertem e os homens - à revelia de suas posições na hierarquia do serviço - são colocados no lugar tradicionalmente ocupado por eles nesses momentos. O prazer de contar o lado espetacular da mobilização em torno de si, por ocasião das partidas de urgência, não deve passar despercebido. Vejamos a semelhança dos relatos: 


\begin{abstract}
“A bolsa arrebentou e eu pensei: 'Estranho... É melhor avisar o diretor.' Liguei pra ele: "Seu Fulano, a bolsa arrebentou." Ele: "E daí?" "E daí que o bebê vai nascer!"; "Como assim, o bebê vai nascer? Não se mexa, eu já estou chegando!" Ele me levou até o helicóptero e os bombeiros me levaram para o hospital, mas o diretor andava em círculos. Parece que ele nem dormiu nessa noite e telefonou para o hospital: "E então, nasceu?" No dia seguinte, foi a educadora que ficou telefonando até as 3 horas quando Théo nasceu."

"Eram 8 horas da manhã quando a bolsa arrebentou; eu não disse nada até o meio-dia. Aí eu disse pro educador: "Acho que deves chamar os bombeiros..."; "O quê? Espere..." Ele entrou em pânico e não parava, indo e vindo do quarto para o escritório. Telefonou para o diretor: "Estou chegando..."; "Você está bem ?" Os dois entraram em pânico. Os bombeiros chegaram e eu disse: "Eu estou bem, mas eles..." Fui de helicóptero e fiquei sozinha na maternidade, logo que cheguei me chamaram ao telefone, era o diretor: "Está tudo bem?" "Tá, tá tudo bem, me deixa tranqüila!" (DIÁRIO DE CAMPO)
\end{abstract}

Os relatos são similares também quando nos levam a concluir que, durante esse período passado na maternidade, ambas não foram pacientes dóceis. Emilie relata sua resistência a respirar da maneira recomendada durante o parto e Estela sua desobediência frente aos conselhos de uma enfermeira que lhe dizia para caminhar no corredor. Estela só teria mudado de atitude no dia em que sua colega de quarto lhe alertou quanto ao risco de uma trombose: "Se eu soubesse que era grave, eu teria caminhado desde o primeiro dia." Considerando que estas mulheres vivem numa instituição em que são cotidianamente observadas e orientadas, podemos pensar que o contato pontual com outros profissionais lhes ofereceu a ocasião de fazer do seu jeito sem que isso repercutisse sobre relações de maior duração, como as que mantém no contexto de CAVAL.

Os relatos contrastam no que se refere ao sentimento de solidão das duas mulheres e informam sobre as diferenças das duas crianças quanto à inscrição genealógica. Desde que veio morar na ilha d'Yeu, Estela não teve mais contato com o pai de sua filha, enquanto que Emilie manteve a relação amorosa com o pai de seu filho. Durante a gravidez, ele esteve muito presente na ilha d'Yeu. Por ocasião das ecografias, ele acompanhava Emilie, que conta orgulhosa: "Ele disse pro médico parar com aquele negócio da ecografia porque pensou que era por isso que o bebê se mexia, que o exame lhe machucava. Ele ficou olhando pra tela com os olhos arregalados." No dia do nascimento, o pai do bebê veio ao encontrou Emilie na maternidade. 
Segundo o que ela relata, sem esconder certa satisfação, sua irmã e o pai de Théo teriam brigado para assistir ao parto e para aparecer nas primeiras fotos. A narrativa acerca do nascimento de Théo culmina com a decisão de reconhecimento da paternidade:

"Ele disse na frente do diretor que ia reconhecer o bebê: 'É claro que vou reconhecê-lo, é meu filho, ele vai ter o meu nome.' Eu fiquei de boca aberta porque ele tinha dito que não ia reconhecer... Ele também disse: 'Eu não tenho dinheiro, mas estou ao lado de Emilie, não tenho recursos financeiros, mas moralmente estou com ela.' O diretor respondeu: 'Já é uma grande coisa!"” (DIÁRIO DE CAMPO)

Além disto, Emilie observa que a família do pai de seu filho - de origem cigana - estaria sabendo do nascimento: "Parece que a família de Saïd festejou o nascimento de Théo, colaram suas fotos na parede e comemoraram durante três dias!"

Estela, no entanto, viveu o nascimento de sua filha solitariamente:

"Eu via as outras mulheres com os papais que perguntavam: 'E então, querida, o bebê está bem?' O pai de Chloé... Eu telefonei pra ele do hospital e ele bateu o telefone na minha cara, nem quis saber de sua filha. Mais tarde ele telefonou, mas aí eu não quis falar com ele. Por isso que eu quis sair logo do hospital.” (DIÁRIO DE CAMPO)

Nos dias seguintes ao parto, as duas mães e os recém-nascidos foram visitados pelos filhos e irmãos residentes na ilha e levados à maternidade por alguém da equipe educativa. Foi a ocasião de tirar as fotos que preenchem os álbuns dos bebês. Aliás, essas duas crianças foram as únicas de suas famílias para quem um álbum de fotos foi confeccionado. Conforme Fine ${ }^{19}$, em seu estudo sobre os diferentes tipos de escrita que marcam a vida das mulheres, a confecção do álbum de nascimento participa, atualmente, da construção da imagem de mãe carinhosa e dedicada. Segundo a antropóloga, nessa confecção as mulheres implicam-se diretamente na construção da biografia da criança, manifestam amor e confundem-se com eles no momento do nascimento.

19 Comunicação Escrituras femininas e ritos de passagem, apresentada no seminário "Antropologia Comparada das sociedades européias e asiáticas", 23 de março de 2000, EHESS. 
Para Emilie e Estela, o apoio da equipe educativa contribuiu para que, apesar do contexto particular em que vivem, disponham de uma espécie de suporte de suas imagens de mãe. Durante nossos encontros, esses dois álbuns eram seguidamente mostrados e comentados. No álbum de Chloé, a pulseira usada na maternidade está cuidadosamente colada ao lado de uma foto "mãe e filha" publicada no jornal regional, na seção de anúncio dos nascimentos da semana: "Os jornalistas vieram no quarto, eu disse pra eles que eu não sou daqui, mas eles disseram que não tinha problema e tiraram a foto mesmo assim." Na casa de Estela, um mural confeccionado com as fotos da recém-nascida e de seus quatro irmãos decora a parede da sala. Na casa de Emilie, a foto de Théo no colo de seu pai na maternidade decora a estante da sala.

Chegando de volta à ilha d'Yeu, Estela apressou-se em convidar uma residente de CAVAL e seu companheiro para serem os padrinhos de Chloé. Emilie não tinha a mesma urgência: "Eu penso em alguém para ser a madrinha de Théo, mas veremos quando eu tiver saído daqui." Talvez esse descompasso quanto à urgência de definir os padrinhos de seus filhos possa ser colocado em relação com a maior solidão de Chloé no momento de seu nascimento.

$\mathrm{O}$ momento do nascimento permitiu às duas mulheres reconhecerem, no olhar e no apoio recebido, alguma coisa de valorizante, relacionada com a maternidade. Isso é particularmente importante se levarmos em conta o que outros estudo ${ }^{20}$ também identificaram em relação à percepção do acompanhamento profissional por parte de mulheres em dificuldade. A saber, a constatação de que suas referências ao olhar sobre si inscrevem-se no registro da queixa. No cotidiano dessa instituição da ilha d'Yeu, as residentes também se queixam do olhar ressentido como um comentário, uma reflexão. Esses olhares, percebidos como avaliativos das maneiras de ser e de agir da mãe, podem ser vividos de forma bastante negativa. No caso das duas mulheres aqui citadas, os primeiros dias do recém-nascido coincidem com a suspensão do olhar percebido como desaprovador. Ainda mais que a dependência física e psíquica que liga os pequenos a suas mães valoriza suas presenças ao

20 DONATI, Pascal et al. Les centres maternels: re'alités et enjeux éducatifs. Paris: L'Harmattan, 1999; LE GRAND-SEBILLE, Catherine. Se laisser affecter par l'autre: approche anthropologique de l'accompagnement. In: DUMONT, Brigitte et al. Accompagner. Paris: Érès, 2000. 
lado deles. Contando seu retorno para a ilha d'Yeu, Emilie observa:

\begin{abstract}
"Fiquei cinco dias no hospital e quando cheguei ao barco um senhor me disse: 'Estávamos lhe esperando!' Eles tinham arrumado tudo. Ocupei a cabine onde tem uma cama e dormi durante toda a viagem. Quando cheguei à CAVAL, a educadora tinha preparado tudo. Nos dias seguintes, ela esteve sempre ao meu lado." (DIÁRIO DE CAMPO)
\end{abstract}

A agradável surpresa dessas acolhidas confirma as observações de Molenat num artigo em que argumenta a favor de uma aliança técnica e relacional na abordagem dos nascimentos em situação de precariedade: "A mãe ou o pai, atingidos em sua segurança interna, assombrados pelo medo de ser julgados, encontram a ocasião de ser reintroduzidos na linhagem dos humanos." ${ }^{21}$ Bonadio ${ }^{22}$, cuja pesquisa foi realizada junto a mulheres grávidas atendidas numa instituição filantrópica no Brasil, demonstrou como a expressão ser tratada como gente sintetiza o que na vivência das mulheres corresponde aos elementos mais significativos dessa passagem pela instituição: a interação efetiva ou o estabelecimento de vínculo de confiança entre elas e as enfermeiras. Scavone, a partir de estudo junto a mulheres da Ilha de São Luís, que vivem com grandes carências de infra-estrutura, observa suas resistências "em irem a uma maternidade, não só por se sentirem menos protegidas afetivamente, como também por não confiarem nos métodos ali utilizados". ${ }^{23}$ Na perspectiva de trazer a experiência parturição para o campo do simbólico ${ }^{24}$, cabe reconhecer que, se em todas as sociedades humanas, o nascimento é cercado de práticas que visam acolher a criança na comunidade dos vivos, quando ele ocorre longe do grupo de pertencimento ou em condições hostis, à margem, são sobretudo os profissionais (da saúde ou da proteção social) que poderão contribuir para o acolhimento e a inserção da mãe e do bebê na linhagem dos humanos.

21 MOLENAT, Françoise. Réapprendre la simplicité des mots et des gestes. In: KNIBIEHLER, Yvonne (Org.). Repenser la maternité. Condé-sur-Noireau: Corlet, 1999. p. 66-70.

22 BONADIO, Isabel Cristina. "Ser tratada como gente": a vivência de mulheres atendidas no serviço de pré-natal de uma instituição filantrópica. 1996. Tese (Doutorado em Enfermagem) - Escola de Enfermagem da USP, São Paulo, 1996.

23 SCAVONE, Lucila. As múltiplas faces da maternidade. In: . Dar a vida e cuidar da vida: Feminismo e Ciências Sociais. São Paulo: Unesp, 2004. p. 151.

24 TORNQUIST, Carmen Susana. Armadilhas da Nova Era. Revista Estudos Feministas, Florianópolis, v. 10, n. 2, p. 483-492, 2002. 